\title{
The Positions of the Cutaneous Components of the Facial Glossopharyngeal and Vagal Nerves in the Spinal Tract of $V^{\prime}$
}

\author{
JAMES ARTHUR TAREN \\ Laboratory of Neurosurgical Research, Department of Surgery, \\ (Section of Neurosurgery) The University of Michigan, \\ Ann Arbor, Michigan
}

Although the debt of the neurosurgeon to the neuroanatomist is virtually incalculable, nowhere is it greater than in the case of surgical interruption of the socalled "pain pathways," where the results reflect the knowledge of the anatomy. One purpose of the present study was to make medullary trigeminal tractotomy a precise operation for the relief of intractable pain deep in the ear and in the region of the angle of the jaw.

Ramón y Cajal (1897) stated that the glossopharyngeal and the vagal nerves transverse the descending tract of $\mathrm{V}$ (fig. 1 ). With customary acumen he suggested that the cutaneous components of these nerves descended in the dorsal one-sixth or one-seventh of the spinal tract of $\mathrm{V}$. However, he was unable to find any terminations of cutaneous components of the facial nerve. Van Gehuchten ('00) initiated the controversy over the location of the cutaneous components of the glossopharyngeal and the vagal nerves since he was unable to demonstrate any degeneration in the descending tract of $\mathrm{V}$ after sectioning these nerves. Kerr ('62), however, has traced, in the cat, descending root fibers of the facial, glossopharyngeal, and vagal nerves to $\mathrm{C} 1$ or $\mathrm{C} 2$ levels, where they ended in the dorsal horn.

\section{MATERIAL AND METHODS}

One method has been to study the degeneration of nerve fibers by Weil and Marchi techniques following rhizotomy of various combinations of facial, glossopharyngeal, and vagal nerves in monkeys. The pattern of somatotopic localization thus obtained in the spinal tract of $V$ has been checked in man by selective medullary trigeminal tractotomy.

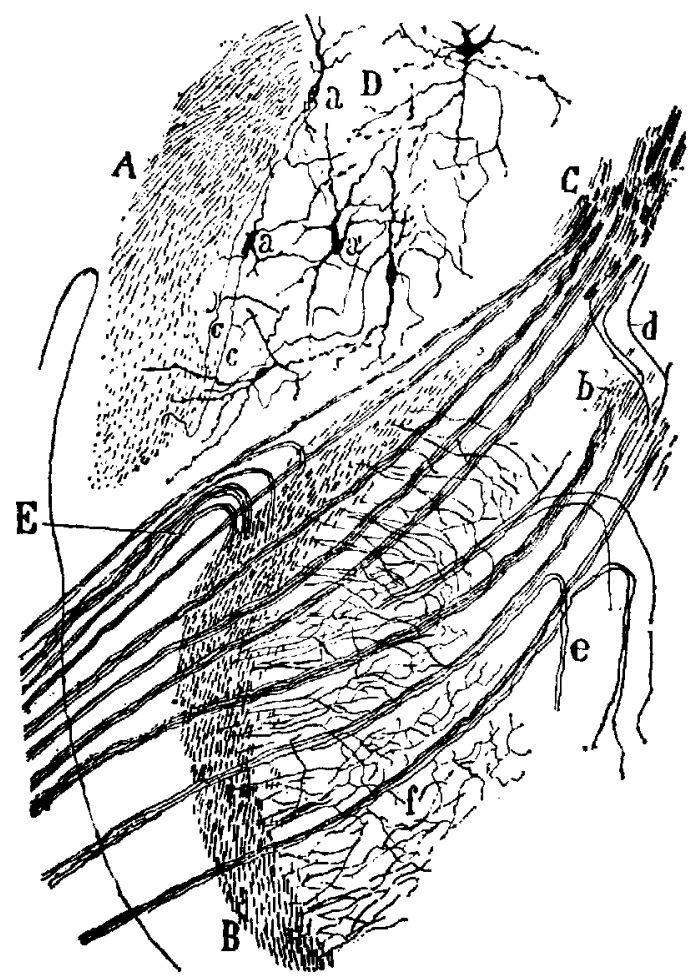

Fig. 1 An illustration from Cajal's work (1897) of a cross section through the medulla of a cat. $E$ are vagus nerve fibers joining the spinal tract of $V$. Other fibers of the vagus nerve traverse this tract on their way to the tractus solitarius and its associated gray. A, Restiform body. B, descending tract of V. C, Fasciculus solitarius. D, position of the descending vestibular pathway. a, cells whose axones go to the Restiform body. b, pathway of the anterior accessory solitarius. $d$, fibers which pass from one Fasciculus solitarius to the other. $c, f$, and $e$ are not labeled in the original work.

1 Presented at the Annual Meeting of the Cajal Club, Minneapolis Minnesota, March 16, 1962. 
Two mature macaque monkeys (Macaca mulatta) were tested to exclude any neurologic deficit. The animals were anesthetized with ether and placed in the face-down position in the headrest. The suboccipital cervical area was then shaved and sterilely prepared. Utilizing full sterile technique, a midline incision was made in the head of each monkey from the external occipital protuberance to the spine of C-2. A suboccipital craniectomy including the rim of the foramen magnum was then done bilaterally. The dura was opened to expose the right cerebellar hemisphere. The cisterna magna was opened and the right cerebellar hemisphere was elevated to expose the facial, the acoustic, the glossopharyngeal, and the vagal nerves. In one animal all of these cranial nerves were divided unilaterally; in the other animal only the glossopharyngeal and vagal norves were sectioned unilaterally. The incision was closed in layers and the animals were allowed to recover.

Numerous neurologic examinations were carricd out on both animals. In the case of the animal with only the glossopharyngeal and the vagal nerves sectioned there was no demonstrable neurologic deficit. However, the animal with all four nerves sectioned demonstrated a peripheral facial palsy on the right and insensitivity of the right eardrum and right auditory canal to pin prick.

The animals were sacrificed on the twenty-first postoperative day using the method of direct injection of $10 \%$ formalin and the brains with attached cervical cords removed and fixed in $10 \%$ formalin. The Swank-Davenport ('35) modification of the Marchi technique was used.

\section{EXPERIMENTAL RESULTS}

As has been shown previously, all three divisions of the trigeminal nerve descend in the spinal tract of $\mathrm{V}$ to $\mathrm{C} 3$ and possibly $\mathrm{C} 4$ in monkey and in man (Dejerine, '14; Humphrey, '54; Sjöquist, '38; Taren and Kahn, '62). The mandibular division is dorsomedial, the ophthalmic division is ventral, and the maxillary division is interposed. These are shown (fig. 2) in a plane at just below the level of the obex. The human spinal tract of V (Taren and Kahn,
'62) has a similar pattern arrangement of the fibers (fig. 3 ).

After sectioning the facial, the glossopharyngeal, and the vagal roots in the monkey degeneration was noted in the dorsomedial portion of the spinal tract of $\mathrm{V}$ as is shown in figure 4 . Figure 5 illustrates the degeneration resulting from sectioning of glossopharyngeal and vagal nerves. Although the degeneration is in the same position, it is much less in amount, from which we must assume that there is, as Foley (' 60 ) found, a considerable cutaneous component of the facial nerve. The caudal extent of the cutaneous components of all three divisions of the trigeminal nerve as well as for the facial, the glossopharyngeal, and the vagal nerves was determined (fig. 6) and found to be approximately the third cervical segment.

From the evidence presented above it is concluded that the cutaneous components of facial, glossopharyngeal, and vagal nerves in the monkey are admixed with the mandibular division of the trigeminal in its dorsomedial location in the spinal tract of $\mathrm{V}$ at lower medullary levels (fig. 7). That this is the correct somatotopic location at this level in man has been corroborated with stimulation techniques (Kunc, '60) and techniques of selective medullary tractotomy.

\section{CLINICAL RESULTS}

Although pain sensation from the face is subserved primarily by the trigeminal nerve in man, a branch of the facial nerve innervates the outside of the ear drum, the glossopharyngeal nerve supplies the auditory canal, the vagal nerve has an occasional cutaneous branch (the ramus auricularis to the ear) and the upper posterior cervical nerve roots subserve the angle of the jaw and overlap the trigeminal distribution. The neural pathway for facial pain is thus surgically accessible at a level 6 to $8 \mathrm{~mm}$ below the obex.

The operation of medullary tractotomy is done with the patient in the sitting position to facilitate exposure. The medullary incision, 4 to $5 \mathrm{~mm}$ in depth, is made at a point 6 to $8 \mathrm{~mm}$ below the obex and extends from the upper bulbar accessory rootlet to a line extrapolated from the posterior rootlets of the second cervical nerve 
root. An adequate incision results in complete analgesia of all three divisions of the trigeminal as well as analgesia in the distribution of facial, glossopharyngeal, and vagal nerves except for sparing of the vermilion border of the lip (fig. 8). A degree of ataxia in the ipsilateral upper extremity usually accompanies effective tractotomy and is caused by compromise of the cuneate fasciculus and the spinocerebellar system. Too anterior an incision in the already crossed lateral spinothalamic tract and the ventral secondary ascending tract of $\mathrm{V}$ may produce analgesia on the contralateral body and face. Our failure in the past to eliminate pain deep in the ear was the result of an incision that was not dorsal enough in extent and was usually accompanied by mandibular sparing. As further evidence for our somatotopic localization of the pain and the temperature components of the facial, the glossopharyngeal, and the vagal nerves, we cite a case (fig. 9) in which medullary tractotomy $6 \mathrm{~mm}$ below the obex spared the entire mandibular division and failed to relieve pain deep in the ear. Revision of the tractotomy by extending the incision 1 to $2 \mathrm{~mm}$ dorsally resulted in analgesia of the eardrum and auditory canal as well as over the distribution of all three divisions of the trigeminal except for a sparing of the vermilion border of the lips. The pain deep in the ear was also completely relieved following the second procedure.

\section{SUMMARY}

The cutaneous components (pain and temperature) of the facial, the glossopharyngeal and the vagal nerves descend in the spinal tract of $\mathrm{V}$ with mandibular division of the trigeminal nerve into the cervical cord. Selective medullary trigeminal tractotomy in man corroborates this.

\section{ACKNOWLEDGMENTS}

The research was supported from funds from the U. S. Public Health Grant B-3620 and also received aid from Parke, Davis \& Company, Detroit, Michigan. For the help from both sources, the author wishes to express his appreciation.

\section{LITERATURE CITED}

Dejerine, J. 1914 Sémiologic des affections $\mathrm{d} u$ systéme nerveux. Paris, Masson \& Cie, $1212 \mathrm{pp}$.

Foley, J. D. 1960 A quantitative study of the functional components of the facial nerve. Am. J. Anat., 107: 237-244.

Gehuchten, A. van 1900 Anatomic du systéme nerveux de l'homme. Louvain, A. UystpruystDieuriommé. Vol. II, p. 77.

Humphrey, T, 1954 The trigeminal nerve in relation to human fetal activity. Res. Publ. Ass. Nerv, Ment. Dis,, 33: 127-154.

Kerr, F. W. L. 1962 Facial, vagal and glossopharyngeal nerves in the cat. Arch. Neurol. (Chicago), 6: 264-281.

Kunc, Z. 1960 La localisation des trajets de la douleur des nerfs IX, X, and VII dans la moelle allongée et la possibilitè de leur tractotomie sèlective. Acta Neurochirurgica, 8: 327324.

Ramón y Cajal, S. 1897 Nueva contribucion al estudio del bulbo raquideo. Rev. Trimest. Micrograf., 2: 67-99.

Sjöquist, O. 1938 Studies on pain conduction in the trigeminal nerve. A contribution to the surgical treatment of facial pain. Acta Psychiat., suppl. 17, 139 pp.

Swank, R. L., and H. A. Davenport 1935 Chlorate-osmic-formalin method for staining degenerating myelin. Stain Tech., 10: 87-90.

Taren, J. A., and E. A. Kahn 1962 Anatomic pathways related to pain in face and neck. J. Neurosurg., 19: 116-122. 


\section{PLATE 1}

EXPLANATION OF FIGURES

2 Photomicrographs of cross sections from macaque medulla. Weil preparations. In ( $A$ ) the arrow indicates degeneration in the descending tract of $\mathrm{V}$ following retrogasserian rhizotomy of all three divisions of trigeminal nerve. In photomicrograph (B) the arrow indicates degeneration in the spinal tract of $\mathrm{V}$ after retrogasserian rhizotomy of mandibular division only.

3 Photomicrograph of cross section of a human medulla in the plane of figure 2 following total retrogasserian rhizotomy for tic douloureux. Weil preparation.

4 Photomicrograph of cross section of a macaque medulla after rhizotomy of facial, glossopharyngeal, and vagus nerves on the right side. The arrow shows degeneration intermingled with the mandibular division of $\mathrm{V}$. Note the overlying dorsal spino-cerebellar tract. Marchi preparation.

5 A photomicrograph of cross section of the medulla of a monkey, Marchi preparation, after rhizotomy of the glossopharyngeal and vagal nerves on the right side. The arrow indicates degeneration which again corresponds to the mandibular localization. 

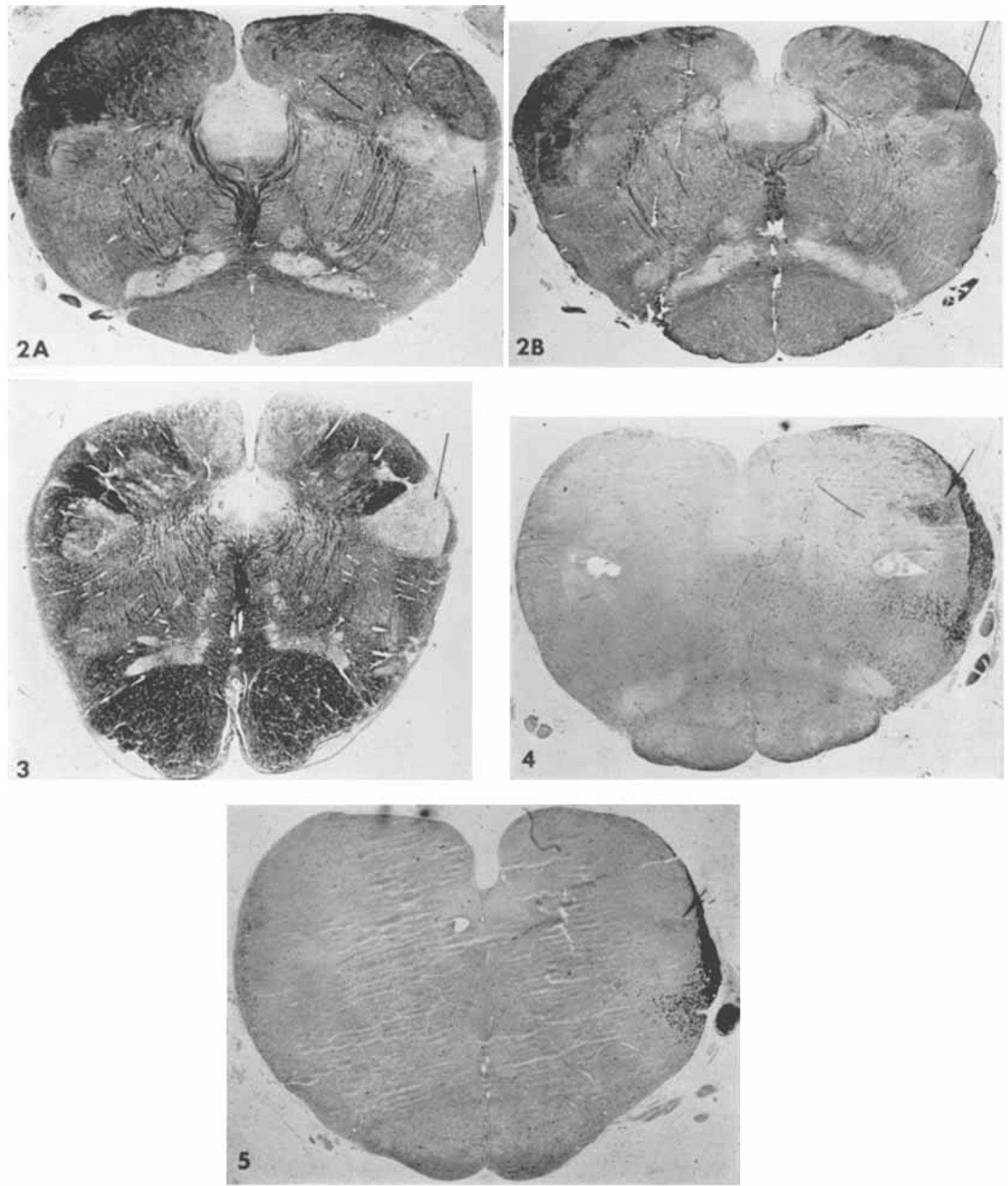

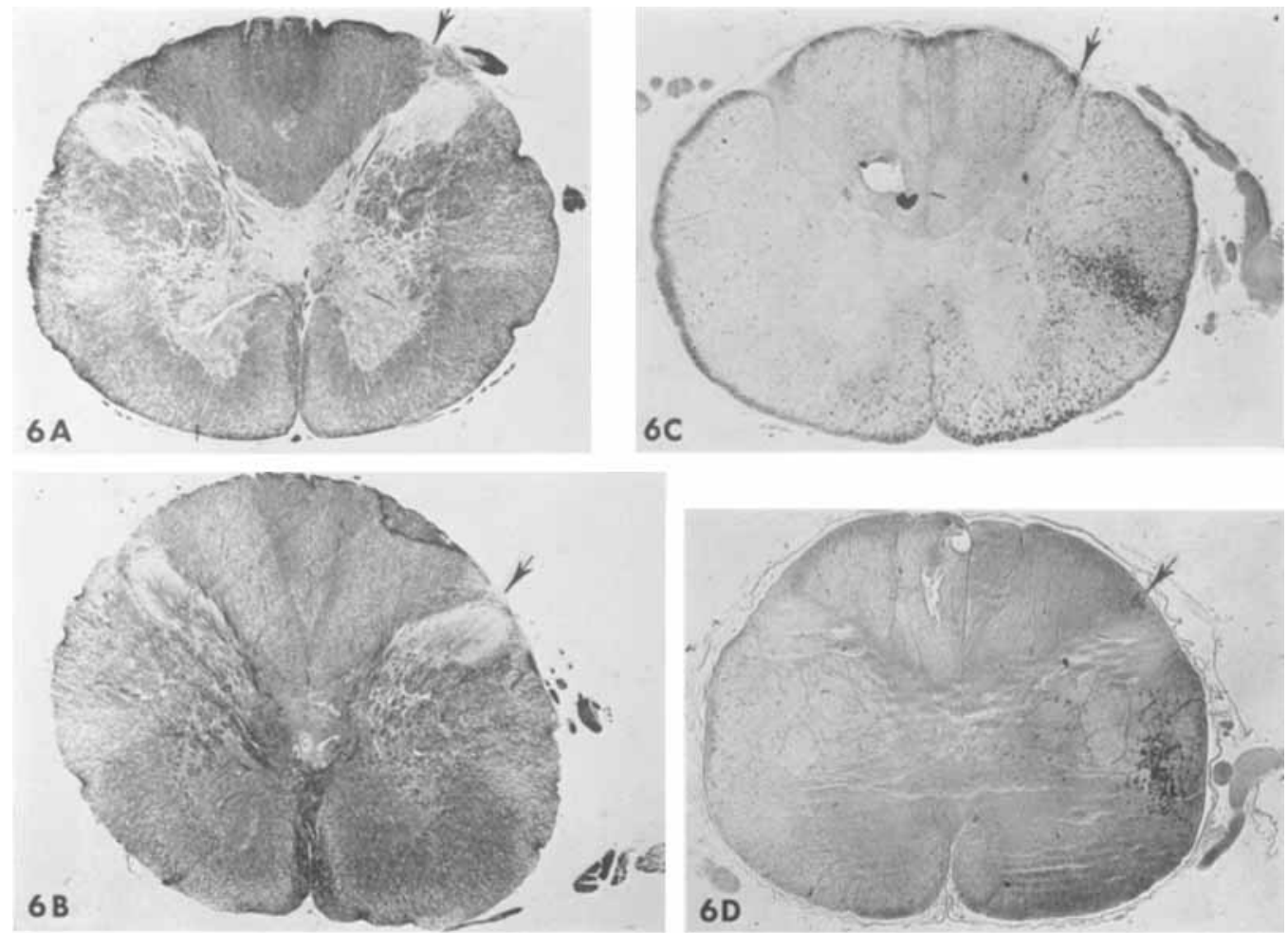

6 Photomicrograph of cross sections at approximately C-1 in four monkeys to illustrate the caudal extent of the spinal tract of $\mathrm{V}$. At (A) the arrow shows degeneration produced by total retrogasserian rhizotomy of trigeminal nerve. At (B) the arrow shows degeneration following retrogasserian rhizotomy of the mandibular division only of the trigeminal. In (C) the arrow indicates degeneration after rhizotomy of the facial, glossopharyngeal and vagal nerves and in (D) the arrow shows degeneration following rhizotomy of the glossopharyngeal and vagal nerves. $\mathrm{A}$ and $\mathrm{B}$ are Weil preparations and $\mathrm{C}$ and $\mathrm{D}$ are Marchi preparations. 


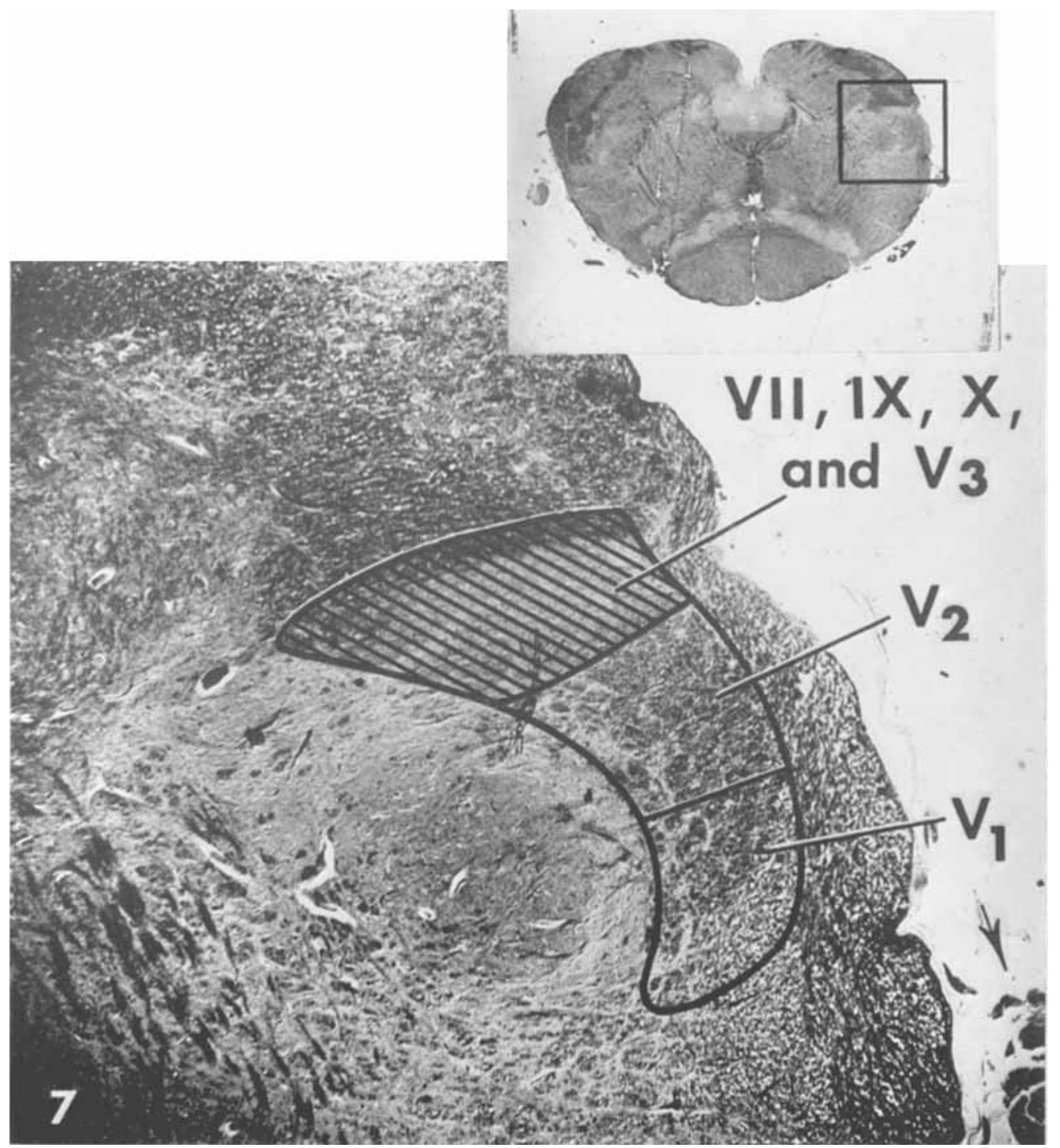

7 A diagram illustrating the pattern of somatotopic localization of the trigeminal, facial, glossopharyngeal, and vagal nerves in the spinal tract of $\mathrm{V}$ at the level of the sensory decussation is presented. This pattern is superimposed upon a photomicrograph of a cross section of medulla of monkey after rhizotomy of the mandibular division of the trigeminal nerve (Weil preparation). The arrow indicates the bulbar accessory rootlet which, in man, delineates the ventral extent of the incision employed in medullary tractotomy. 


\section{PLATE 4}

8 This is a retouched photograph of a patient who suffered intractable pain from a carcinoma of the tongue. Medullary tractotomy was performed on the left side. The horizontal cross-hatching delineates the area of analgesia produced by the tractotomy except for sparing of the vermilion portion of the lip and in this case a portion of the upper lip. The vertical striping indicates the zone of anesthesia produced by posterior rhizotomy of the second, third and fourth cervical nerve roots which was employed in addition to the tractotomy to render the cervical incision painless and to ablate the area of sensory overlap at the angle of the jaw. In addition there was analgesia of the eardrum and auditory canal. Postoperatively the patient was free of pain.

9 These are retouched photographs of a patient suffering intractable pain from carcinoma of the tongue. (A) illustrates the sparing of the mandibular division of $V$ after the first operation. In addition there was sparing of the auditory canal and eardrum. (B) shows the area of analgesia following a dorsal extension of the medullary tractotomy. Following the second operation sparing was limited to the vermilion border of the lip, which is usual. In addition the eardrum and auditory canal on the right was analgesic and the patient free of pain. 

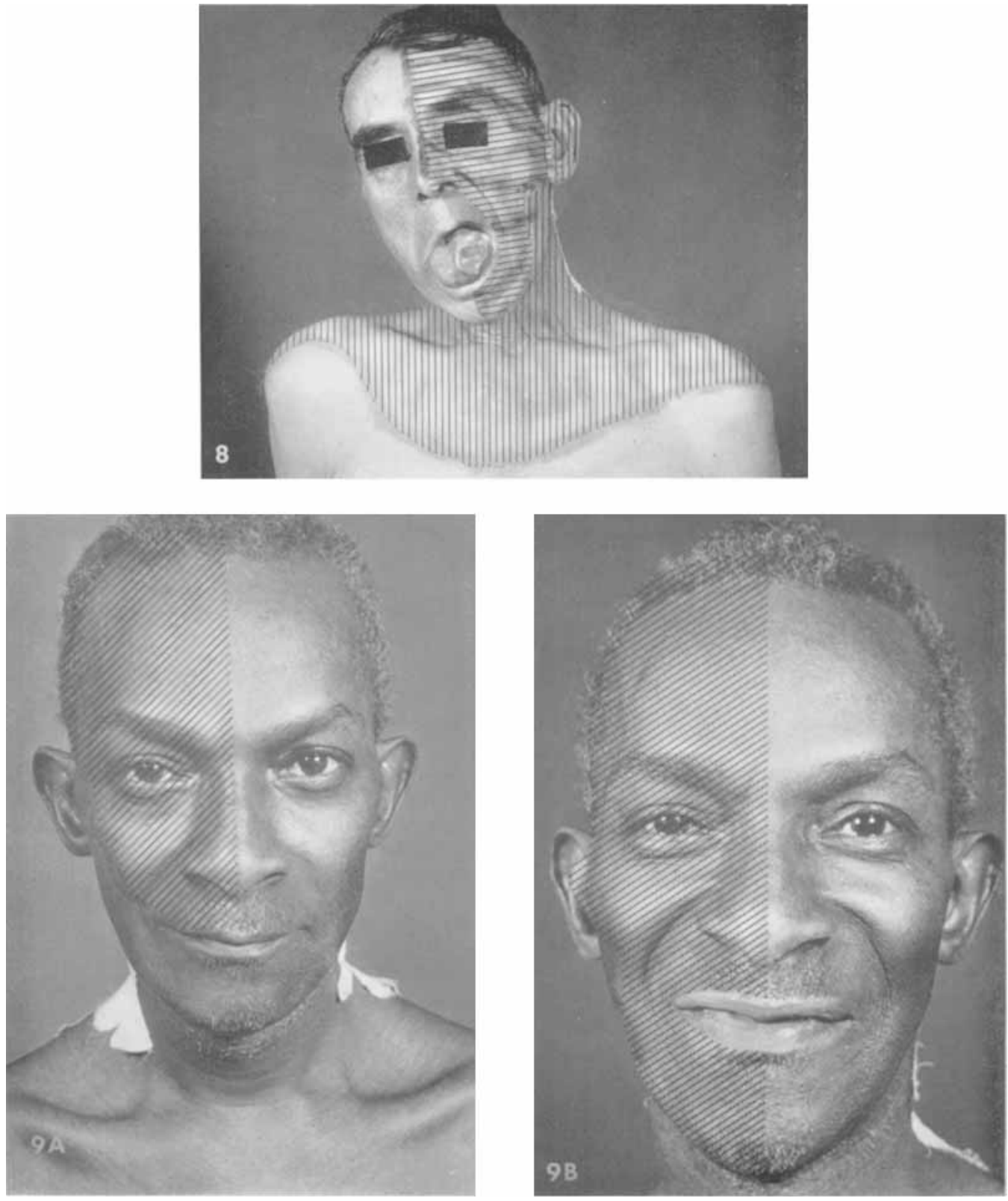